\title{
RESENHA
}

\section{PLANTÃO PSICOLÓGICO, NOVOS HORIZONTES}

\section{Rosilene LINARES}

O livro "Plantão Psicológico: novos horizontes", apresenta de forma clara e objetiva o desafio que os diversos autores se propuseram vivenciar implantando o serviço de Plantão Psicológico com base humanista, em diferentes contextos institucionais.

A presente obra está estruturada em 8 capítulos e 1 prefácio, sendo este último escrito por Wood, o qual distingue o Plantão Psicológico de uma conversa entre amigos, e aponta-o como uma produtiva forma de aprendizagem para estagiários uma vez que possibilta a ampliação do papel da psicoterapia. Wood, considera que o Plantão Psicológico está bem próximo da origem latina da palavra planton, que significa plantar. Neste sentido, o livro para ele está repleto de boas novas, pois apresenta um Plantão Psicológico "tendo seus pés no chão", pois procura ser prático e responder às necessidades atuais de quem o procura. Além disso, associa-o ao sentido de plantar enquanto enraizar, uma vez que, as experiências relatadas nos capítulos seguintes mostram um serviço inserido na cultura brasileira, perfeitamente vivo e em fase de crescimento.

O capítulo de introdução é de autoria de Mahfoud, organizador do livro. Neste capítulo, Mahfoud ressalta que, desde 1987, a então semente do Plantão Psicológico no Brasil, como modalidade de um Aconselhamento Psicológico, vem passando por transformações que buscam atender a realidade social rompendo com a teorização rígida de inúmeras psicologias e permitindo se experimentar a vitalidade de uma experiência que se a princípio era vista como uma técnica alternativa, atualmente é encarada como um trabalho metodologicamente rigoroso, sistemático, fruto de observação e pesquisas com base fenomenológica. Este autor salienta ainda, que o leitor encontrará na presente obra muito mais provocações que modelos, sendo que "uma das provocações significativas é a integração de trabalhos de base humanista inseridos em instituições".

No capítulo seguinte, Rosenthal apresenta o Plantão Psicológico enquanto uma "proposta de atendimento aberto à comunidade", no Instituto Sedes Sapientiae em São Paulo. Fundado em 1975 este Instituto oferece serviços de ensino e pesquisa nas áreas da Psicologia e da Educação, "estimulando todos os valores que acelerem o processo histórico no sentido de justiça social, democracia, respeito aos direitos da pessoa humana."

A proposta de criar o serviço de Plantão Psicológico nesta Instituição foi da Dra. Rosenberg que inspirada nas experiências das "walk-in clinics", surgidas nos Estados Unidos, já vinha oferecendo este serviço à população que procurava no Instituto de Psicologia da USP o atendimento regular em aconselhamento psicológico, o qual tinha como referencial teórico a Abordagem Centrada na Pessoa. 
Acreditando que as atitudes pilares da Abordagem Centrada na Pessoa (empatia, congruência e aceitação incondicional) associadas ao desenvolvimento das potencialidades inerentes à pessoa e à possibilidade de estimulação dessas potencialidades, pudessem beneficiar a população, que em determinado momento da vida necessita de alguém que a escute de forma diferenciada, sem necessariamente ter que se submeter a psicoterapia tradicional, o Plantão Psicológico foi oferecido pela primeira vez neste Instituto em agosto de 1980 como um "curso de expansão" supervisionado e coordenado por Rosenthal, que através de seus alunos oferecia atendimento psicológico aberto à população.

A autora destaca que o Plantão Psicológico não foi criado para acabar com as filas de espera do Instituto, nem para fazer triagem e muito menos com a pretensão de substituir a psicoterapia. O objetivo era oferecer à comunidade um novo tipo de serviço. Este teve a duração de três semestres, atendendo 145 pessoas ( $52 \%$ eram mulheres e $48 \%$ homens) com profissões e grau de escolaridade diversificados. As avaliações efetuadas pelos clientes, através de comentários escritos a respeito do Plantão, apontaram desde a importância de ser ouvido, o alívio após o desabafo até a "frustração da expectativa de que pudessem receber atendimento prolongado".

De forma geral, Rosenthal aponta essa experiência como amplamente válida, uma vez que conseguiu ser presença mobilizadora para o cliente e para o plantonista. Destaca que para o plantonista foi possível superar o estereótipo de que a eficácia da ajuda psicológica está diretamente associada à duração do atendimento, além de experimentar uma prática diferente da oferecida no período de graduação.

Por fim, a autora faz uma reflexão sobre o ouvir, enquanto ser presença por inteiro diante do outro, estar concentrado no cliente e em si mesmo, apontando a Abordagem Centrada na Pessoa como um referencial teórico bastante adequado para o Plantão Psicológico.

O terceiro e quarto capítulos abordam uma experiência de Plantão Psicológico na Escola vivenciada como desafio por Mahfoud numa escola de classe econômica "A", e por Drummond, Brandão, Silva e Mahfoud numa escola pública de $2^{\circ}$ grau num bairro operário na periferia de Belo Horizonte (MG). Em ambas as escolas o Plantão Psicológico foi oferecido como um espaço para o aluno enquanto pessoa dotada de um potencial inovador e criador.

Na primeira escola a divulgação do senviço se deu através de folhetos com trechos da música "Quase sem querer" do grupo Legião Urbana e histórias em quadrinhos envolvendo alguns comentários a respeito do Plantão. Os alunos responderam de forma positiva à proposta e aos poucos. O que era inicialmente curiosidade foi se agregando como um espaço onde a pessoa era privilegiada e não o problema. O fato do trabalho estar inserido num contexto institucional e como tal, dever responder às demandas da mesma, exige do profissional uma constante criatividade no desenvolvimento de novos métodos e instrumentos que atendam às necessidades e estejam no âmbito das contribuições da Psicologia.

A experiência de Mahfoud neste sentido se deu no processo de Orientação Profissional e no trabalho de prevenção ao uso de drogas. Para a Orientação Profissional a Instituição sugeriu a aplicação de testes, mas Mahfoud e Brandão utilizaram trechos de músicas e poemas brasileiros, adaptaram o Método de História de Vida apresentado por Julius Huizinga no IV Fórum Internacional da Abordagem Centrada na Pessoa, no Rio de Janeiro em 1989 e eventualmente testes de personalidade. Para trabalhar o tema drogas, criaram o primeiro material brasileiro de Educação Afetiva, que procura modificar 
fatores pessoais considerados disponente à utilização de drogas (como auto-estima, identidade, resistência a pressão de grupo etc.) sem necessariamente enfocar o tema drogas.

A atuação destes profissionais nos remete ao fato de que embora inseridos numa instituição, esta não tem necessariamente que ditar todas as formas de atuação, pelo contrário, ela deve ajudar o profissional a encontrar caminhos novos, este é o sentido do trabalho que mobiliza.

O Plantão Psicológico na escola pública surgiu dessa primeira proposta dirigida pelo professor Mahfoud, o qual procurou aproveitar os recursos pessoais e materiais de seus estagiários, bem como os recurso da própria instituição, inserida num contexto comunitário muito ativo.

Sendo um dos objetivos do serviço de atendimento em Plantão Psicológico a mobilização do aluno, estabeleceu-se que este teria plena liberdade para procurar o serviço e que em nenhum momento haveria encaminhamento por parte dos professores e da direção. Tal postura permitiria ao aluno buscar o Plantão como um espaço para "rever, repensar e refletir suas questões", na certeza de que encontraria em qualquer horário de aula alguém disponível para escutá-lo, por isso, os estagiários estariam presentes nos três períodos de aula, de segunda a sexta-feira, e no sábado de manhã.

Para que esta proposta fosse vista pelos alunos como algo atraente e não como um serviço "pra doido" utilizou-se como recurso de apresentação, a música e o teatro. Num determinado dia, durante o recreio, os estagiários começaram a tocar músicas já conhecidas no meio jovem, a distribuir panfletos com a explicação do que seria o Plantão Psicológico e dramatizar a vivência de um adolescente que se sentia incompreendido pela sua família. O intuito de tal apresentação era tocar o adolescente no que diz respeito às suas próprias inquietações e oferecer-lhe a oportunidade de falar sobre isso. O resultado apareceu logo no dia seguinte, quando os alunos começaram a procurar o Plantão Psicológico.

Após um semestre de atendimento, surgiu a necessidade de sistematizar os dados dessa experiência na tentativa de "entender com clareza as necessidades daqueles sujeitos" e posteriormente, dar um retorno à instituição para que essa pudesse rever suas posturas. O primeiro passo foi adotar uma metodologia fenomenológica que propiciasse categorizar as demandas trazidas pelos alunos a partir dos relatórios escritos pelos estagiários. Partindo da discussão do tema central de cada atendimento elaborou-se 15 categorias, além de uma "demanda indeterminada" caracterizada pelo aparecimento de várias questões importantes durante o atendimento ou pela não identificação de nenhuma demanda claramente definida.

As demandas categorizadas foram: "dificuldade com drogas", "insatisfação com as atribuições e contingências", "preocupações com conseqüências de ações ou decisões passadas", "dificuldade em fazer escolhas", "elaboração de perdas", "arrependimento e culpa", "sexualidade", "dificuldades com a escola", "busca de reconhecimento", "incômodo com a maneira de ser e de reagir às situações", "desconfiança nos relacionamentos", "insatisfação nos relacionamentos com a família", "falta de correspondência nos relacionamentos amorosos", "falta de reciprocidade nos relacionamentos já estabelecidos" e "obter opinião profissional".

Este levantamento permitiu verificar que algumas questões (gravidez na adolescência, professores, direção, abuso de álcool e violência) que tanto a escola como os profissionais esperavam que fossem diretamente abordadas pelos alunos, acabaram aparecendo como temas subjacentes à real situação que os perturbava. Assim sendo, é 
importante atentar para a necessidade de se ter a atenção centrada na pessoa e não nas expectativas anteriormente criadas a partir de determinados valores e vivências.

Mahfoud e seus colaboradores finalizam o capítulo ressaltando três aspectos significativos dessa experiência de Plantão Psicológico em escola pública. Primeiramente, que o Plantão Psicológico mobilizou não só os alunos envolvidos no processo, mas a própria instituição, incluindo a direção e os professores, os quais se permitiram olhar o aluno como uma pessoa dotada de talentos que precisam encontrar espaço para a expressão.

Em segundo lugar, que é importante identificar as pessoas com as quais se pode contar na instituição, uma vez que existem aquelas que apoiam o trabalho e aquelas que o boicotam. E finalmente, que é necessário ter sempre firme a proposta inicial, retomando-a junto a direção, aos professores e aos alunos.

No capítulo seguinte, Mahfoud, Drummond, Brandão e Silva buscam compreender o processo de cada atendimento efetuado no Plantão Psicológico nesta escola pública, numa tentativa de "identificar suas fases, as mudanças de rumo e o movimento que a pessoa realizava durante a sessão", bem como, avaliar de forma mais rigorosa esse tipo de intervenção. O material de pesquisa foram 56 relatórios previamente selecionados, descrevendo 37 casos de alunos atendidos.

As fases identificadas foram: " $A Q$ - apresenta a questão", "AH ou ExQ - apresenta a história da questão ou explora a questão", alguns alunos apresentavam várias questões "AV-apresenta várias questões" ou "OQ-outra questão" ou ainda "AmQ - amplia a questão", "PI - pede informação" e "Ol - obtenção da informação", "RA - reafirma atitude", "NC - não comparece ao atendimento marcado mas volta numa nova sessão", "RQR - relata como a questão se resolveu", "RQ - retoma a questão",
"RCA - relata como agiu","PR- propõe-se a refletir" e "AP-apresenta possibilidades".

No que diz respeito ao encerramento do processo, foram identificadas três fases que indicam o caminho percorrido pelo sujeito, ou seja, "MP - mudança de perspectiva", "ANA - assume nova atitude" e "DA - decide agir."

Tendo categorizado as fases, o trabalho seguinte consistiu em descobrir a seqüência de aparecimento das mesmas. Analisando o conjunto dos casos, verificou-se uma certa semelhança, pois algumas fases ( $\mathrm{AQ}, \mathrm{AH}$ ou AV) aparecem no primeiro atendimento e outras (MP, ANA e DA) no final do atendimentos, além, é claro, das particularidades de cada história.

Essa atividade de pesquisa procurou sistematizar uma experiência subjetiva narrada no Plantão Psicológico sem a pretensão de enquadrar tal processo em padrões rígidos e previsíveis, pelo contrário, foi uma tentativa de apreender os diversos movimentos de mudança decorrentes deste tipo de intervenção.

No quinto capítulo, Cautella Junior apresenta a sua experiência de Plantão Psicológico num hospital psiquiátrico, destacando que este serviço contribuiu para que a instituição reformulasse a sua postura frente ao indivíduo institucionalizado. Primeiramente o autor faz uma breve descrição do hospital, relatando ser um hospital de " porte médio e de curta permanência que atende pacientes do sexo feminino em quadro agudo de doença mental." Além do serviço de psicologia, o hospital conta com psiquiatras, terapeutas ocupacionais, assistentes sociais, recreacionistas e enfermeiros.

O serviço de Plantão Psicológico, nesta instituição, nasceu em 1992 como uma alternativa terapêutica, uma vez que as práticas tradicionais de atendimentos individuais e de grupo vinham apresentando algumas limitações, particularmente decorrentes da situação de que a instituição exercia uma 
certa pressão para que o indivíduo se vinculasse à psicoterapia e também pela dificuldade do psicoterapeuta eleger o foco que realmente era prioritário para o cliente, no caso da psicoterapia breve.

O enfoque teórico adotado foi a Abordagem Centrada no Cliente e o procedimento imediato consistiu em disponibilizar psicólogos que estariam num lugar pré estabelecido, por um determinado tempo. Os pacientes foram informados deste serviço pelos próprios profissionais e também através de cartazes.

Cautella Junior destaca que o " nível de ansiedade, irritabilidade e agitação dos internos diminui significativamente após o plantão psicológico" Outro aspecto ressaltado é que a participação nos grupos deixou de ser efetuada por pressão institucional e passou a ser uma opção do cliente, o mesmo ocorrendo com os atendimentos individuais. Os encaminhamentos internos e externos também sofreram alterações e tronaram-se mais eficientes.

Embora de forma geral, os internos tenham respondido de forma positiva ao serviço de plantão, algumas limitações foram encontradas no que se refere a pacientes com depressão profunda, quadros catatoniformes e pessoas com delírios graves.

Após quatro anos de funcionamento, umserviço semelhante foi oferecido aos familiares dos internos, diferenciando-se do atendimento que já era oferecido pelo serviço social e pelo corpo médico. No plantão psicológico, a família encontraria espaço para manifestar seu malestar e outras questões decorrentes do fato de terem um membro da mesma, institucionalizado. No decorrer de três anos de funcionamento a demanda aumentou significativamente, inclusive gerando uma nova situação, o aumento da procura do serviço após o cliente principal já ter tido alta.

Encarando a instituição como um cliente em potencial, o plantão psicológico também foi estendido aos funcionários, diminuindo os problemas de relacionamento entre os mesmos, e conseqüentemente gerando um campo terapêutico bem mais eficiente. Esse serviço, por uma questão ética, foi prestado por um profissional de fora da instituição.

Desta forma, podemos afirmar que o plantão psicológico pode ser um instrumento de promoção da saúde, uma vez que "não modifica somente aquele que é o alvo da intervenção"e se pensarmos que a mudança é um fator indispensável ao desenvolvimento podemos afirmar ainda, que o Plantão Psicológico é um meio extremamente promotor de desenvolvimento.

O sexto capítulo aborda o Plantão Psicológico na Clínica-Escola da Pontifícia Universidade Católica de Campinas, implantado em 1994, a partir do projeto de dois alunos do Curso de Especialização em Psicoterapias Institucionais do Departamento de Psicologia Clínica.

No presente capítulo, Cury aponta que embora inspirado no modelo de Aconselhamento Psicológico desenvolvido no Instituto de Psicologia da USP, o serviço de Plantão Psicológico da PUC-Campinas funciona com uma inovação, ou seja, a integração de supervisores de abordagens teóricas diferenciadas (cognitivista e centrada no cliente). Portanto, as diferenças teóricas foram ultrapassadas tendo em vista uma" uma ajuda psicológica que se mostrasse mais empática aos apelos da comunidade, neste contexto e época", salvaguardando a autonomia de cada supervisor no que diz respeito às estratégias clínicas.

O oferecimento deste serviço se deu devido ao alto índice de desistência da clientela que ao procurar a Instituição enfrenta longas filas de espera, bem como em decorrência de algumas pessoas buscarem ajuda na clínica numa situação emergencial. Os plantonistas, alunos do último ano do curso de Formação de Psicólogos, embora não cubram todos os 
horários de funcionamento da clínica, oferecem o atendimento no Plantão Psicológico sem agendamento atendendo pessoas que livremente buscam ajuda para problemas de natureza emocional.

Tecnicamente a ação do plantonista consiste em oferecer ao cliente que procura o serviço, o acolhimento adequado para que possa explicitar a "demanda emocional que o aflige" naquele momento, o que dá ao atendimento um caráter imediato, sem visar necessariamente encaminhamentos psicoterápicos. Desta forma, o foco do atendimento não é a queixa em si, mas a pessoa, numa tentativa de conferir-lhe autonomia e facilitar a reflexão na busca de alternativas para enfrentar as dificuldades que experiencia.

Embora o Plantão Psicológico represente um avanço, Cury atenta para dois fatos importantes. Primeiro, para o risco de se tentar colocar neste serviço, a solução para todos os problemas que envolve o sistema Público de Saúde Mental, e segundo, para a urgência de evitar reproduzir nas clínicas-escola, os consultórios particulares. Para ela, cabe ao plantonista, criar um contexto mais próximo de um modelo comunitário, onde a população possa verdadeiramente ter voz e desenvolver uma certa autonomia emocional.

Relata ainda, que uma das grandes contribuições da implantação deste serviço tem sido a transformação das pessoas envolvidas neste processo (supervisores, estagiários e clientes), possibilitando pesquisas que podem contribuir em muito para a transformação das clínicas-escola de Psicologia.

A vivência deste plantão foi descrita numa recente pesquisa qualitativa com base fenomenológica onde foram analisados depoimentos de supervisores, plantonistas e funcionários da Clínica-Escola da PUC-Campinas. O resultado demonstra que o Plantão Psicológico se apresenta como um atendimento clínico bem mais flexível, que pode gerar uma certa economia para o sistema, uma vez que efetua encaminhamentos internos e externos, oferecendo uma relação de ajuda eficaz e diminuindo as listas de espera. Ao estagiário-plantonista possibilita uma compreensão mais ampla da comunidade, um contato com pessoas e problemas diversificados e até inesperados, possibilitando o desenvolvimento do raciocínio clínico, além de um amadurecimento pessoal e uma maior autonomia em sua prática clínica.

No último capítulo, Psicólogos de Plantão, Cury apresenta uma reflexão a respeito das inúmeras contribuições da Psicologia Humanista, particularmente da Abordagem Centrada na Pessoa, que iniciando pela psicoterapia individual, grupos intensivos, encontros de comunidade, chega ao pronto atendimento psicológico amplamente infocado neste livro, oferecendo uma nova forma de intervenção, cuja autenticidade dependerá em muito do psicólogo-plantonista, o qual não pode permitir que este tipo de serviço seja mais uma forma de "ludibriar a população."

Afirma ainda, que profissionais e cidadãos psicólogos não podem ignorar as inúmeras dificuldades presentes no contexto Latino Americano e muito menos negar a missão transformadora que cada um é chamado a exercer eticamente na instituição ou contexto em que atua. Para Cury, é necessário estar sempre de plantão, no sentido de ter "coragem para superar dogmas e entusiasmo para buscar o inédito. “

Numa linguagem bastante acessível e atraente, os autores conseguem atingir o objetivo de comunicar a seriedade de uma experiência de Plantão Psicológico em diferentes contextos, possibilitando ao leitor acompanhar historicamente o desenvolvimento deste serviço em nosso país, bem como os desafios que entremeiam a sua prática. 


\section{REFERÊNCIA BIBLIOGRÁFICA}

MAHFOUD, M; DRUMMOND, D.M; WOOD, J.K; BRANDÃO, J.M; ROSENTHAL, R.W;
SILVA,R.O; CURY, V.E; CAUTELLA JUNIOR,W. Plantão Psicológico: novos horizontes. São Paulo, Companhia llimitada, 1999. 